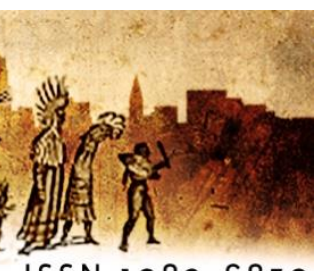

\title{
Lamber o mundo com a própria língua erótica e política em Ricardo Domeneck
}

\section{Lick the world with your own tongue erotica and politics in Ricardo Domeneck}

Gustavo Silveira Ribeiroi (UFMG)

\begin{abstract}
Resumo: Estudo da relação entre erotismo e política na poesia de Ricardo Domeneck, em cujo centro está o corpo e o desejo. O artigo considera com mais ênfase o mais recente livro de poemas do autor, Odes a Maximin.

Palavras-chave: Poesia brasileira contemporânea; Ricardo Domeneck; Erotismo. Política.
\end{abstract}

Abstract: Study of the relationship between eroticism and politics in Ricardo Domeneck's poetry, in the center of which is body and desire. The article focuses more on the author's most recent book of poems, Odes a Maximin.

Keywords: Contemporary Brazilian poetry; Ricardo Domeneck; Eroticism; Politics.

\section{O corpo e a Pólis}

Que a poesia é força disjuntiva, energia paradoxal da linguagem, já se sabe: anterior à própria literatura e seus códigos, anterior aos ritos civilizatórios que desenvolvemos para a arte da palavra, a poesia se situa no intervalo entre natureza e cultura, sendo ao mesmo tempo movimento vital, impulso quase orgânico do corpo que quer sair de si, expandir-se em voz e gesto, e invenção 
codificada e convencional de modos de dizer o mundo, descrevendo-o, revelando-o - como nas cosmogonias e nos cantos pastoris, por exemplo -, e também de intervir sobre ele, convocando as suas forças elementares ou interrompendo o seu fluxo cego, como acontece nos poemas e imprecações xamânicas, nos poemas-prece da tradição judaico-cristã. Ligada visceral e inseparavelmente ao corpo, desde suas origens sagradas e performáticas até os nossos dias - em que pese as muitas formas de abstração da oralidade e do gestual que, no Ocidente, tiveram lugar nos últimos séculos -, a poesia tem no erotismo (essa religião particular e profana do corpo) uma referência contínua, uma zona de convergência estável. Como nos lembra Octavio Paz em La llama doble, o amor e o desejo, o sexo e a pulsão fusional, atributos de Eros, são elementos incontornáveis da experiência simbólica humana, modos de conhecimento de si e do outro que passam pela carne e dela se dirigem ao restante das coisas e seres existentes (cf. PAZ, 1994, p. 12-13). O erotismo expõe o que se esconde em pleno dia, num jogo entre ocultamento e revelação. Essa mecânica ambivalente é também parte decisiva da operação poética: a passagem, no coração do real, da coisa à palavra, da palavra à coisa, descreve os movimentos do poema, que nem completamente desvela o mundo, nem o encobre de todo. A luta da linguagem consigo mesma dá acesso a uma área desconhecida da própria linguagem: a surpresa da poesia. Do mesmo modo, a tensão e a busca pela unidade que subjaz à manifestação do erotismo fazem emergir o que, no corpo, é mais do que o corpo - um suplemento difícil de mensurar.

Aproximar-se do dado erótico e suas máscaras e sucedâneos (a coisa amorosa, a energia disruptiva da pornografia, o universo do sagrado) é, no poema, aproximar-se do canto inaugural que, desde tempos imemoriais, celebra as funções do corpo, os prazeres complexos do encontro e da mistura dos sexos, o milagre do ventre fértil e os mistérios que as zonas escuras da matéria carregam. Para além das listas e das genealogias, para além da evocação dos mortos e das glórias militares, tarefas mundanas e espirituais que couberam à enunciação poética mais antiga (a epopeia e os registros pedagógicos, os hinos e lamentos fúnebres) a poesia surgirá mesmo como fenômeno lírico quando se 
transformar em canção da carnalidade, celebração profana da matéria viva e do tempo presente, do gozo que faz suspender os sentidos e falhar a linguagem, incapaz de traduzir a consumação do corpo e a elevação afetiva em palavras articuladas, plenas de direção e significado. Conforme se dá a ver na tradição grega arcaica (especialmente em Safo) e no universo hebraico anterior ao Cristo (com o Cântico dos cânticos, por exemplo), um diferente modus operandi da poesia é posto em questão com o erotismo: o canto breve, a consagração do agora, a centralidade atribuída aos sentidos inventam o sublime e dão ao sagrado um outro lugar - distante dos rituais e dos nichos, despojado de altares e sacerdotes - muito mais próximo da vida cotidiana com sua brevidade e circunstâncias, suas ninharias e especificidades.

É nesse sentido, portanto, do tempo presente e da vida comum, logo também da política e da intervenção direta em tudo o que é vivo, que se deve compreender o gesto criativo (e também crítico e historiográfico) de um poeta como Ricardo Domeneck, que vem, desde o seu primeiro livro, Carta aos anfíbios, de 2005, e do início de sua atividade pública, procurando reposicionar o erotismo na cena poética brasileira ${ }^{1}$, fazendo dele um campo de força a partir do qual pensar não só os seus próprios gozos e lástimas, mas também algumas das contradições mais agudas do seu tempo.

O que importa em Domeneck não é o sujeito isolado, voltado sobre si, elaborando paciente as suas questões interiores: é o corpo na Pólis, seus desejos e tormentos tornados públicos, propedêutica para a consideração em detalhes da condição de estrangeiro, hoje (época do recrudescimento de nacionalismos, práticas autoritárias e movimentos que reivindicam, num giro terrível da História, purezas de solo e sangue) mais próxima que nunca da condição do pária e do refugiado. O corpo tornado público serve também para a crítica dos desequilíbrios entre as línguas e as culturas (imperiais e impositivas umas,

\footnotetext{
${ }^{1}$ Além de seus poemas, nos quais procura pensar o problema aqui colocado, Domeneck tem escrito resenhas e ensaios nos quais procura destacar a tradição (tantas vezes renegada) da poesia erótica no país, resgatando textos e autores pouco conhecidos ou de todo não lidos nessa chave de compreensão. Como editor da franquia eletrônica da revista Modo de usar \& co., propôs séries temáticas e pequenas coletâneas sobre o assunto, colocando o corpo (ou a ausência dele) como ponto de interesse.
} 
subalternizadas e rebelionárias outras, e isso não só no plano internacional, mas também em escala local - daí a atenção dada ao poeta a todas as formas de localismo e regionalismo linguístico, seu uso contínuo e bastante consciente do dissídio entre a abstração normatizante da língua oficial e o realismo terra-a-terra das variações menores, dos desvios dialetais e os desdobramentos ético-políticos que eles carregam); serve ainda, para a defesa insistente dos sexos e afetos incômodos, tolerados (em certas épocas e em algumas partes do mundo) mas não de todo aceitos, implicados num circuito de constrangimentos e violências que, em nossa época e em boa parte do Ocidente, parecem menores e pacificados, mas que na verdade ainda estão bastante acesos, como a crescente onda conservadora tem demonstrado (com o seu cerco às liberdades homoafetivas) e a própria pesquisa histórica empreendida pelo poeta vem revelar, na medida em que tantos dos seus poemas são construídos em diálogo com formas e personagens do passado, muitos dos quais (Antínoo, poetas árabes medievais, amantes anônimos martirizados, atrizes de Hollywood como Maria Schneider, o poeta Federico García Lorca, entre outros) tragados, de um modo ou de outro, pela higienização disciplinadora dos corpos e dos desejos.

Os poemas de Domeneck, nesse sentido, ganham unidade quando repetem, em constantes variações, o ato arcaico de voltar os seus olhos e sua atenção para os interstícios do corpo humano e neles localizar tanto a metafísica possível (o infinito, o transcendente, o Belo) quanto a origem mesma (suposta, imaginada) da obra de arte e da poesia, na medida em que muitos dos deles vão apresentar, na crueza da nomeação vulgar e da descrição direta, o corpo como palco privilegiado, território de onde emana a urgência de representar (registrar, arquivar, transmudar) o real, oferecendo dele uma nova faceta. Inscrever-se, traduzir-se: gestos inaugurais da arte que se fazem, na obra do poeta de Bebedouro, justamente como enunciação do que há de mais íntimo na própria carne.

A promessa da plenitude, a perversão do gasto: talvez entre esses dois campos amplos, que são também dois sentidos distintos (entre outros) do erotismo, se movam boa parte dos poemas de Ricardo escritos desde 2011, a partir da guinada que significou a publicação de Cigarros na cama, livro que traz 
ao primeiro plano a dimensão amorosa da sua poesia. O que equivale a dizer sobre esses poemas: de um lado, alguns deles frequentam o enlevo e a melancolia, contrapartes de um encontro com o outro que abole, momentaneamente, os limites do eu e a solidão abissal, o ensimesmamento a que todo indivíduo, por definição, está condenado; trata-se da aspiração utópica, tantas vezes de fundo sacralizante, que o erotismo contém - e também da tristeza que a consciência final da incompletude traz consigo. Por outro lado, várias outras peças desdobram-se na fulguração do instante e na alegria furiosa da transgressão, do desconhecimento das leis morais e dos vários interditos que procuram regular, em perspectiva autoritária, os arranjos mesmos da vida. O poema como festim orgiástico das palavras ${ }^{2}$, no qual a liberdade vocabular e imagética é contígua ao desregramento dos sentidos e ao desrecalque do sexo, que se torna matéria central, referência absoluta de textos abertamente substantivos, que chamam pelos seus muitos nomes as porções fundamentais da anatomia amorosa do homem.

Há um outo aspecto ainda do entrelaçamento de erótica e política na obra de Domeneck. Recorde-se, entretanto, o seguinte: feito um dia morada de Deus (de um deus único, possessivo e zeloso de tudo o que lhe pertencia), no período de consolidação do monoteísmo das religiões do Livro, o corpo deixou de pertencer aos homens, que foram perdendo, através dos séculos, direito e domínio sobre os seus movimentos e vontades, reentrâncias e formas. Tudo o que é sagrado, o filósofo italiano Giorgio Agamben nos lembra, deve ser interdito às mãos e ao toque - às vezes até mesmo aos olhos (cf. AGAMBEN, 2007, p. 6869). A sacralidade reside no mistério e na distância, e é uma forma radical de despossessão. O que o erotismo faz, como a poesia do autor de Medir com as próprias mãos a febre tantas vezes demonstra, pode ser compreendido como um

\footnotetext{
${ }^{2}$ Numa compreensão algo diferente da que propõe Georges Bataille sobre a relação entre poesia e erotismo (cf. BATAILLE, 2004), em Ricardo Domeneck não é a linguagem que se dissolve, perdidos os seus limites, como efeito da força desejante que os atravessa. Ao contrário: a dissolução mística do eu (da língua, da identidade) que tantas vezes caracteriza a literatura erótica dá lugar, na sua poesia, a uma pulsão nominativa que remete à Antiguidade Clássica, às referências greco-latinas (Safo, Catulo, Propércio) continuamente referidas pelo poeta, que parece antes preferir recordar e celebrar, descrever e convocar o corpo, suas fomes e devaneios, a perder-se na atitude extática que ameaçam levar ao colapso a razão e a linguagem.
} 
modo particular de profanação, e como tal, de novo em sintonia com Agamben, um modo profundamente político de restituição: a pele que se entrega ao toque e à contemplação do outro, a boca que enuncia aos gritos o seu próprio prazer, o sexo que se oferece, em flor, ao contato com outros sexos, trata de restituir a si mesmo, isto é, ao próprio homem, o seu corpo. Subtraindo o corpo ao controle simbólico do poder (temporal e religioso), o poema erótico de Domeneck procura devolver aos homens (antes de tudo ao sujeito lírico desses textos, ao ego que os move e assinala) a posse daquilo que the é mais íntimo e seu, mais próprio e precioso: a sua pele, superfície porosa ávida por acoplar-se a outras texturas, outros orifícios, distintas cavidades. Através da palavra poética, o homem pode furtar a si momentaneamente dos olhos vigilantes do Estado, da culpa e da civilização para entregar-se, restituído, aos usos comuns do prazer, do gasto e da subversão. É o que nos recorda essa poética obsessiva, textualidade inquieta, em estado de permanente construção. Para discutir mais detalhadamente os termos dessa erótica política, passo à leitura sistemática de seu penúltimo livro, Odes a Maximin, de 2018.

\section{Cantarolar-te: infectar/inventar outra língua}

A mistura de tempos e referências, o amálgama de corpos amantes, a indeterminação de limites e sentidos são alguns dos elementos que estão no centro do penúltimo livro de poemas de Domeneck, que se estrutura, em todos os seus níveis, como matéria impura, feita de reapropriações, intertextos, intentos disruptivos. Desde a capa, é possível observar que o livro se apresenta sob o signo duplo da hibridação: acima do título, de memória evidentemente classicizante - e disposto em caracteres sóbrios, letras brancas contra fundo azul - encontra-se um desenho ligeiro, de traços quase rudes, que mostra um homem nu lutando contra um enorme peixe. Apoiada sobre o animal, a figura humana tem os joelhos no chão, seus braços esticados procuram dominar a presa, o rosto está voltado para baixo. Nada nessa imagem sugere o equilíbrio e a estabilização das formas que a referência greco-latina mobiliza, nem mesmo há qualquer 
lembrança do universo pictórico ou da estatuária da Antiguidade. Ao contrário, o desenho do artista alemão David Schiesser é moderno, inquieto e descontínuo. As linhas que o constituem em nada se comunicam com os modos de composição clássicos, seu imaginário e procedimentos: é antes um desvio, cujas linhas remetem à paródia e ao universo da caricatura (conforme a sequência das imagens, disposta em meio aos poemas, revela). A convivência, no mesmo plano, dessas duas esferas de significação é uma síntese breve e efetiva da poética que se afirma e espraia no interior do volume. Observando-a, é possível distinguir a proximidade do arcaico e do contemporâneo, da elevação lírica e do humor autoirônico, entre tantos outros pares opostos, que se encontram, nos versos de Domeneck, mesclados e quase indiscerníveis, postos, ao mesmo tempo, em tensão e em diálogo. Línguas, formas, sexos e culturas se tocam e se confundem nesses poemas, que oscilam entre contrários, equilibrando-se, extraindo sua força do material heteróclito que lhe serve de base.

As odes que o poeta escreve se sabem tardias e deslocadas. Pertencem a um tempo desencantado, cantam-se numa língua bárbara, entremeada de muitos outros idiomas, códigos e idioletos, fragmentos de linguagens costuradas com habilidade, sobrepostas umas às outras. A sua potência de invenção reside precisamente aí: a consciência da distância que o poeta mantém da tradição - de seus textos nucleares e das promessas particulares de cada gênero - faz com que ele os possa recuperar e repropor livremente, sem nenhum tipo de subserviência obediente nem de iconoclastia absoluta. Endereçando-se à tradição, remetendo os seus textos ao universo mental da poesia antiga, o poeta pode inscrevê-los, no presente, na temporalidade múltipla das sobrevivências e das reescritas, revelando o que há, na noção mesma de origem (da poesia, da civilização, do Ocidente), que vai implícita no aceno à cultura greco-latina, de impropriedade e incerteza. As suas odes, Domeneck parece afirmar, são tão compósitas quanto os seus referentes de Grécia e Roma, uma vez que, como tantas outras antes e depois, foram estas sociedades e culturas que se estabeleceram a partir do diálogo com o passado e da incorporação deliberada de modelos diversos, de padrões e hábitos e valores de outros povos, outras épocas. 
Nesse sentido, a celebração que o poeta paulista faz da "fuzarca abençoada/de corpos após a Queda" (DOMENECK, 2018, p. 19) não se refere, como se verá, apenas ao contexto alemão e à liberação de fronteiras internas e externas que resultou num incremento de migração e emigração na Europa pós1989. A elaboração eficaz do verso, que se interrompe justo na imagem da Queda (reservando o Muro à linha seguinte, num dos muitos enjambements do livro, um dos fundamentos técnicos mais bem explorados pelo poeta), coloca o leitor diante da ambiguidade do sentido e de referências míticas de outra extração - o Velho Testamento e a judeidade antiga -, que apontam para a mistura indiscernível de coisas que passou a definir o mundo dos homens, distinto, nesse sentido, da claridade ordenadora do Paraíso de que a humanidade fora expulsa, espaço edênico da separação e da hierarquia. A mistura de raças e procedências, referida no poema, é imagem que reúne em si não apenas o dado histórico imediato, mas serve também de baliza para todo o projeto que nas Odes a Maximin se consolida: mais do que os outros volumes do poeta, esse é um livro de quedas, misturas, reendereçamentos, perversões.

A preponderância do erótico nos poemas de Domeneck (constante em todos os seus trabalhos, renovada com vigor neste último) ganha aqui mais uma camada de sentido, por assim dizer. Porque não se trata, no livro, tão somente de celebrar a beleza e as virtudes amorosas de certo M., o "divino rapaz" (DOMENECK, 2018, p. 19) que o poeta esconderá sob o nome de Maximin, em referência a um dos mitos poéticos cultuados pelo escritor alemão Stefan George e seu círculo de interlocutores. Erguido em torno às odes, essa tarefa jubilosa, de alta voltagem sexual, o dado erótico atravessa o conjunto dos poemas irá vindicar também, no mesmo passo, a miscigenação e a multiplicidade incontrolável das heranças, a liberdade dos encontros homoafetivos (furtivos ou não), os modos subversivos que o desejo tem de ampliar a vida e desfazer as tramas unívocas do poder, opondo-se a fronteiras, nacionalidades e proeminências coloniais.

Afirmando a sua condição estrangeira, a um só tempo de imigrante latinoamericano e de poeta menor, que escreve numa língua periférica e quase desconhecida, Domeneck sabe, no entanto, a sua ambígua condição. Ainda que, conforme afirma, "sou meteco/não grego/são esparsos/os meus privilégios" 
(DOMENECK, 2018, p. 21), a possibilidade do canto desestabiliza o jogo, já que coloca o sujeito poético em condição de fazer das canções amorosas lugar de reflexão sobre a dignidade das letras (seu diminuto arsenal) diante das imposições violentas da História. Essas mesmas canções, nas intrincadas linhas sonoras e imaginativas que as constituem, deixam perceber, mais uma vez, o coeficiente político de tudo o que é erótico, na medida em que, se Eros é desmedida e indeterminação, tudo o que passa pelo seu espectro desorganiza as formas do controle, destrói os laços que mantêm os indivíduos (e as comunidades) retirados e imunes, fechados sobre si, em identidades estéreis. Se o erotismo é capaz de virar pelo avesso a gramática e a lógica, como tantos outros poetas já mostraram, Domeneck lembra que Eros também subverte a ordem da Pólis, já que possibilita, a seu modo, que cantores estrangeiros (metade bárbaros, metade cidadãos) - parte dos sans-papiers, esses que "advém/eles também/de gentes/ por séculos/sem/passaporte?" (DOMENECK, 2018, p. 85) -, possam, como amantes, momentaneamente tomar o lugar que por direito pertenceria às jovens esposas, genitoras potenciais de uma nova geração de famílias proeminentes e guadiãs, ao fim e ao cabo, do arranjo imutável dos estamentos do Estado, da ordem natural das coisas. O chamado que o poeta faz à descolonização, convocando o amante "teutojudeujudoca" (DOMENECK, 2018, p. 87) a participar de uma orgia de línguas e sexos passa igualmente por aí.

Uma das forças fundamentais do livro, a virulência dos afetos é a senha de passagem do um ao outro, do uno ao múltiplo. Se a mistura, como já se disse, ocupa lugar privilegiado na feitura dos poemas, isso se dá principalmente pela representação do sexo e do amor. Lembrado, imaginado, buscado com ardor, o corpo do parceiro é a porta aberta para a saída de si, para o indeterminado da experiência erótica que interrompe, pelo tempo suspenso do desejo, o fio da identidade: o eu se esvazia, quer fazer-se todo porosidade ["Quantas vezes pedi a orixás e santos/Maximin, fazer de mim todo ânus" (DOMENECK, 2018, p. 97)], ser tão só um servo do objeto de seu tesão; e até depois de morto, enfim, o poeta quer ter o coração inerme do rapaz voltado para si: "Só peço: a oeste do teu torso/para que dessarte o teu miocárdio ao menos/aponte em flecha na direção dos meus restos" (DOMENECK, 2018, p. 45). Um verso em especial, dentre tantos 
exemplos possíveis, concentra, em nível semântico, sintático e até morfológico, esse impulso fusional, a vontade de possuir e pertencer, a um só tempo, (a)o amante. O trecho, colhido no poema que abre as Odes a Maximin, precisa, para ser melhor compreendido, de uma certa moldura, o verso que the vem antes e os que estão postos logo depois:

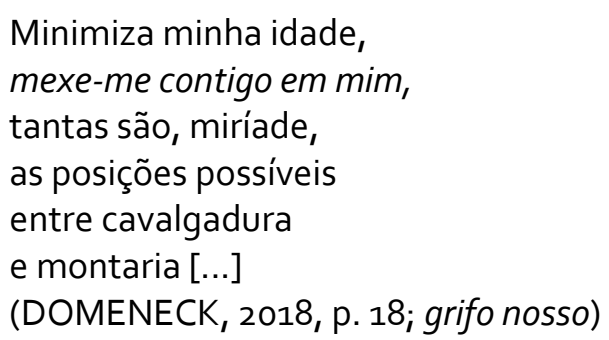

A ânsia de ultrapassar a própria pele (de tê-la atravessada) manifesta-se, antes de tudo, como uma forma de desconcerto momentâneo da linguagem. O poeta, nesse passo, ignora os contornos do mundo e formula, num misto de súplica e comando - que é também um jogo de palavras com o nome do amante - a demanda ilimitada: "mexe-me contigo em mim". Verso de ritmo e corte precisos, ele se estrutura na delicadeza das sílabas que oscilam entre o $\mathrm{M}$ e o $\mathrm{Ne}$ procura desfazer, pela sua força paradoxal, a inteireza do eu que o enuncia. Seja pelo arranjo sonoro criado pela melodia, seja pela proximidade quase indiscernível dos corpos que, conforme sugere a imagem, se imbricam e deslimitam, o sujeito da escrita busca desconhecer-se, uma vez que penetra e é penetrado, é conteúdo e continente ao mesmo tempo. O desejo ambíguo de ser trespassado e assimilado por Maximin passa também pelo verso anterior, no qual o poeta pede que o amante retenha a passagem dos anos e faça o tempo voltar atrás. O jogo de contrários proposto a partir do nome próprio, Maximin, confere densidade adicional às súplicas, já que revela desejo de ser o outro, espelhar-se nele, ter a sua idade, habitar o seu corpo. Mais do que recuperar um punhado de referências à cultura clássica (segundo a qual a convivência amorosa entre um homem adulto e um adolescente era marcada, muitas vezes, por uma aguda e trágica consciência do peso dos anos e das angústias que eles carregam consigo), os versos de Domeneck propõem também reflexão sobre outros sentidos da experiência erótica, que para o poeta vão combinar, incontornavelmente, a dor e 
o gozo, a ferida narcísica e o gesto expansivo de uma vida que se quer múltipla e irrestrita.

Aspecto igualmente importante no conjunto geral das Odes a Maximin, a relação entre poesia e homoerotismo se deixa ver em praticamente todo o livro, perceptível desde o título. Afinal, sem Maximin e sua "belezura berbere", não existiriam as odes. Sem a pujança das visitas intermitentes e a memória do seu prazer, não haveria a celebração dos poemas, às vezes feita de força alegre, às vezes vazada em ironia agridoce. As odes existem, sobretudo, para monumentalizar o instante, que aqui é ainda mais fugaz posto que clandestino, oculto sob o anonimato da metrópole (Berlim, onde Domeneck reside desde 2005) e os disfarces dessas ficções do enamoramento que são, afinal, as máscaras amorosas que o poeta forja. Mas, para além de todas as celebrações da virilidade e dos interstícios do amante, a operação que irá soldar de modo mais preciso a afetividade desviante do universo queer e a fatura da poesia lírica se dará numa peça curta, talvez despretensiosa do ponto de vista formal, mas bastante significativa para a poética que Ricardo Domeneck vem desdobrando diante de seus leitores, tanto nas Odes quanto em outros de seus livros (com destaque para Ciclo do amante substituível [2012] e Medir com as próprias mãos a febre [2014]).

Os cantores antes de mim

Como aquele Oscar de Londres e suas odes a Bosie.

Como Constantino de Alexandria e seus cantares a anônimos.

Como o tal Pedro de Casarsa e seus hinos ao Ninetto.

Ou até certo Ricardo de Bebedouro obcecado com o Moço, tudo o que quero, Maximin, é cantarolar-te.

Tira de sobre as tuas orelhas esses cachos.

Escuta. Aplaude.

(DOMENECK, 2018, p. 43)

O poeta se insere numa tradição particular, como se vê, agora tratando de nomear os pares com quem sabe estar dialogando. Como Dante na Comédia, que traz para junto de si Virgílio e faz dele guia da travessia sinuosa do Inferno e do 
Purgatório, Domeneck se aproxima de uma constelação de poetas modernos que, como ele, fizeram convergir em suas obras o passado remoto, com seus ecos gregos, e a vida contemporânea, numa mistura anacrônica de tempos e mitos. São poetas do desejo, todos eles, marcados pela paixão homoerótica que definirá, num certo sentido, os seus versos e as suas vidas. Os três, Oscar Wilde (1854 - 1900), Konstantinos Kaváfis (1863 - 1933) e Pier Paolo Pasolini (1922 1975), foram também tocados pela violência moralizante e reacionária de seu tempo que, em razão de seus textos e amores gay, a um levou ao cárcere e à ruína; a outro obrigou a uma espécie de silêncio melancólico, feito de renúncia e recolhimento; ao terceiro, por fim, trouxe a morte brutal, perpetrada por assassinos que destruíram o seu corpo, dilacerando-o de modo atroz. Ainda como Dante, o poeta brasileiro se inscreve nesse grupo de espectros sabendo-se pequeno, mas ainda assim digno da companhia elegida. Tanto é que Domeneck inclui-se duas vezes nessa linhagem, já que, junto aos poetas mencionados, figura também um certo "Ricardo de Bebedouro/obcecado com o Moço", numa referência a si mesmo que dobra a aposta da identificação projetiva e confirma a necessidade de, nesses poemas, outrar-se, reinventar a sua voz e a sua assinatura, "escorraçar/os fantasmas/de natais passados" (DOMENECK, 2018, p. 13; grifos do autor).

Num aceno entre soberbo e humilde, o poeta inclui-se nesse cânone desviante, no mesmo momento em que, assinalando a sua condição aprendiz, diz "cantarolar", sem nenhuma grandiloquência, as suas odes, em escolha verbal precisa, na qual se lê tanto uma vênia aos mestres quanto um modo de atualização, em contexto nacional e ordinário, da grandeza das referências mobilizadas - nesse sentido, sua destreza lembra a de Oswald de Andrade, que num imenso e político poema de amor, fez descer à rua e ao trópico os Cantares de Salomão, acrescentando-Ihes a instrumentação brasileira e popular: "Cântico dos cânticos para flauta e violão" (1942). E há mais: o poema em tela, enumerando cantores e sua procedência territorial, remete o leitor atento ao universo dos trovadores e do Medievo europeu, numa nova volta do tempo sobre si. Os líricos gregos antigos, os poetas-itinerantes do amor cortês e do trobar clus, os artífices modernos de uma poesia intempestiva, escrita nos últimos dois 
séculos - todas essas referências e todas essas épocas vêm se imiscuir no poema de Domeneck, ampliando a esfera dos diálogos sustentados pelo poeta (e que deve incluir também, nesse livro tão onívoro e multitudinário, nomes como os de Walt Whitman, Hilda Hilst, poetas árabes antigos e cantoras indígenas kuikuro), que de todos eles se apropria e a cada um deles se endereça, numa reproposição contínua de formas e sentidos.

Falsamente apresentado como "arte povera" (DOMENECK, 2018, p. 49), as Odes a Maximin, ao contrário, pertencem a um poeta muito cheio de recursos, cioso da sua técnica e das inúmeras histórias do seu ofício. Feitos tantas vezes com retalhos de leituras e oralidades várias, os poemas de Ricardo Domeneck são capazes de emular a forma modelar dos clássicos, com suas convenções e decoros, assim como se revelam sempre prontos a saltar sobre os escombros da tradição e organizar, a partir de seus detritos, novas possibilidades expressivas, novos modos de pensar o mundo que nascem, ou podem nascer, da contemplação "dos músculos fartos" (DOMENECK, 2018, p. 45) de um jovem mestiço. O canto ligeiro e a meia voz do poeta ('cantarolar' não quer dizer, nesse contexto, outra coisa) não se entrega fácil, pois esconde, mais do que revela ao primeiro olhar, a dimensão de sua força contestatória.

\section{Referências bibliográficas}

AGAMBEN, Giorgio. Elogio da profanação. In: Profanações. Trad. Selvino José Assmann. São Paulo: Boitempo, 2007.

ANDRADE, Oswald. Poesias reunidas. São Paulo: Companhia das Letras, 2016.

BATAILLE, Georges. O erotismo. Trad. Cláudia Fares. São Paulo: Arx, 2004.

DOMENECK, Ricardo. Carta aos anfíbios. Rio de Janeiro: Bem-Te-Vi, 2005.

DOMENECK, Ricardo. Ciclo do amante substituível. Rio de Janeiro: 7Letras, 2012.

DOMENECK, Ricardo. Cigarros na cama. Rio de Janeiro: Berinjela, 2011.

DOMENECK, Ricardo. Medir com as próprias mãos a febre. Rio de Janeiro: 7Letras, 2014 . 
DOMENECK, Ricardo. Odes a Maximin. Rio de Janeiro: Garupa, 2018.

PAZ, Octavio. A dupla chama. Trad. Wladyr Dupont. São Paulo: Siciliano, 1994.

i Professor da Faculdade de Letras e do Programa de Pós-Graduação em Estudos Literários da UFMG. Publicou, entre outros, O drama ético na obra de Graciliano Ramos (ed. UFMG, 2016); Poesia contemporânea: reconfigurações do sensível (Quixote + Do Editoras Associadas, 2018) e Antevéspera, noite anterior: ensaio sobre a poesia de Age de Carvalho (Macondo Edições, 2018).

E-mail: gutosrı@yahoo.com.br 